\title{
Anthropometric Measures and Insulin Resistance in Rural Indian Adolescents
}

\author{
Bhattacharya $\mathbf{S}^{1,2 *}$, Smith $\mathrm{GD}^{3}$, Shah $\mathrm{SH}^{1,4}$, Ben-Shlomo $\mathrm{Y}^{5}$ and Kinra $\mathbf{S}^{6}$ \\ ${ }^{1}$ Duke Global Health Institute, Duke University Medical Center, Durham, NC, USA \\ ${ }^{2}$ Duke Translational Research Institute, Duke University, Durham, NC, USA \\ ${ }^{3}$ MRC, Translational Centre, Bristol, UK \\ ${ }^{4}$ Division of Cardiovascular Medicine, Duke University Medical Center, Durham, NC, USA \\ ${ }^{5}$ School of Social and Community Medicine, University of Bristol, Bristol, UK \\ ${ }^{6}$ Department of Epidemiology and Population Health, London School of Hygiene and Tropical Medicine, London, UK
}

\begin{abstract}
Aims: To evaluate the relationship of anthropometric measures with insulin resistance (IR) in 1162 Indian adolescents from the follow-up survey of the Hyderabad Nutrition trial.

Methods: Analysis was done on data collected from 1162 adolescent participants of the Hyderabad Nutrition trial follow up survey. Participation included an interview, physical examinations and blood draws. Associations of body mass index (BMI), fat mass index (FMI), fat free mass index (FFMI), central to peripheral skinfold ratio (CPR), percent of body fat, waist circumference (WC) and waist-hip ratio (WHR) with IR were studied using linear regression models accounting for village clustering and adjusting for age and pubertal stage. Anthropometric indices were calculated from height, weight, skinfold thickness, waist and hip circumferences and IR was calculated by the homoeostasis model assessment (HOMA).
\end{abstract}

Results: We observed strong associations of BMI, FMI and FFMI with HOMA. Interestingly, FFMI ( $\beta$ ( $95 \%$ confidence interval) $-0.03(0.01,0.06) ; P=0.007$ (girls) and $0.06(0.03,0.09) ; P<0.0001$ (boys)) was as strongly associated with IR as $\operatorname{BMI}(0.03(0.01,0.06) ; P=0.006$ (girls) and $0.06(0.03,0.09) ; P<0.0001$ (boys)) and FMI $(0.03(0.01,0.05) ; P=0.02$ (girls) and $0.05(0.02,0.07) ; P=0.001$ (boys)) We explored the relationship of lean mass with IR relative to fat mass and the associations remained strong.

Conclusions: We conclude that lean mass is as strongly associated with IR as fat mass in rural Indian adolescents. These findings appear contrary to the belief that higher rates of IR in South Asians reflect greater central adiposity. Future research needs to increase our understanding of the underlying mechanisms that lead to these associations in both obese and lean populations.

Keywords: Adolescents, Anthropometry, Body Composition, Body Mass Index, IR

\section{Introduction}

The rates of diabetes in India are rising dramatically, with the number of people with diabetes projected to rise to 57.2 million by 2025 [1]. The diabetes epidemic, in part, can be explained by the rapid globalization leading to westernizations of diets, more sedentary lifestyles, and transitions from rural to urban living. As observed in adults, South Asian children and adolescents have high rates of IR compared to children and adolescents of other ethnicities [2]. IR predicts the future risk of cardiovascular disease (CVD) [3]. Additionally Indian adolescents have an increased sensitivity to adiposity, high percent of body fat, abdominal obesity and high subcutaneous fat levels $[4,5]$. Studies in adolescents have shown that obesity, particularly visceral obesity, is associated with the development of IR in this age group, with evidence of a $50 \%$ increase in IR in overweight adolescents with every half unit increase in body mass index (BMI) [6-8].

There has been a growing interest in studying different anthropometric measures as indicators of IR and diabetes; especially to understand the increased susceptibility of leaner Indian populations to diabetes. Measurement of WC is a useful measure of obesity-related diabetes risk in Indians, who are more prone to abdominal obesity at normal BMI $[9,10]$. Additionally, Indians have greater amounts of visceral adipose tissue and a higher percentage of body fat than individuals of European ancestry [11,12]. Percent of body fat and central obesity (measured by WHR) as compared to generalized obesity (measured by BMI) have been evaluated as risk factors for diabetes with conflicting reports in Indian populations. In the INTERHEART study, waist hip ratio was the strongest marker of myocardial infarction in South Asians, followed by waist circumference and then BMI [13].

There is lack of consensus on a single anthropometric measure as the best indicator of IR in adolescents. WHR, WC and BMI showed similar correlations with fasting insulin and IR in Chinese children [14]. In Greek schoolchildren BMI, WC and waist-to-height ratio were highly associated with IR [15]. Subscapular skinfold thickness better identified fasting hyper insulinemia than BMI and WC in urban Indian adolescents, however this study did not have data on sexual maturity, which may play an important role on insulin sensitivity in adolescents [16].

Our objective was to evaluate the associations of anthropometric measures with IR in a cohort of rural Indian adolescents who are leaner than their urban counterparts and represent a different socio-economic

*Corresponding author: Sayanti Bhattacharya, Duke Global Health Institute, Duke Translational Medicine Institute, MURDOCK Study 310 Trent Drive, Room \#330 Durham, NC 27707, USA, Tel: 919-613-4405; E-mail: sayanti.bhattacharya@duke.edu

Received February 22, 2014; Accepted July 21, 2014; Published July 23, 2014

Citation: Bhattacharya S, Smith GD, Shah SH, Ben-Shlomo Y, Kinra S (2014) Anthropometric Measures and Insulin Resistance in Rural Indian Adolescents. J Biosafety Health Educ 2: 118. doi:10.4172/2332-0893.1000118

Copyright: (C) 2014 Bhattacharya S, et al. This is an open-access article distributed under the terms of the Creative Commons Attribution License, which permits unrestricted use, distribution, and reproduction in any medium, provided the original author and source are credited. 
stratum of Indian society. A better understanding of this relationship in adolescents will shed more light on the mechanisms and risks involved with development of early IR, a predictor of adverse health outcomes later in life.

\section{Materials and Methods}

\section{Design of the follow up survey of the Hyderabad Nutrition Trial}

Details of design of the Hyderabad Nutrition trial and the follow up survey have been previously published [17]. All adolescents born to participants of the Hyderabad Nutrition trial during the years 1987-1990 were eligible to participate in the follow up study and were included in the current analysis. Participants were recruited from 29 Indian villages. Participation included completion of an interview administered via a questionnaire, clinical examinations and collection of fasting blood samples by a venous blood draw and a brief interview of the mothers. Height, weight, skinfold thickness at four sites, waist and hip circumference, blood pressure and temperature were measured [17]. Data collection was done from 2003 through 2005. The Ethics committee of the National Institute of Nutrition of India, Hyderabad approved the study. Village heads and their committees in each of the 29 villages approved the study as well. In our study we have 1162 adolescents between 12-18 years of age, including 535 girls and 627 boys.

\section{Physical examination}

All measurements were conducted in light, minimal clothing and no shoes. Weight was measured by a digital weighing machine (Model HD 305; Tanita, Japan) to the nearest $100 \mathrm{gm}$ and height was measured to the nearest $\mathrm{mm}$ by a portable plastic stadiometer (Leicester height measure; Chasmors Ltd, London, UK). WC was measured on the bare skin with a non-stretch metallic tape, at the midpoint between the iliac crest below and the costal margin above. Hip circumference was measured in a single layer of light clothing at the widest part, between the greater trochanter and the lower buttock level, with the legs together. The arm measurements were made on the non-dominant side of the participant, with the arm flexed at 90 degrees. A Holtain skinfold caliper calibrated to $0.2 \mathrm{~mm}$ was used to measure the thickness of the skinfolds. Triceps skinfold thickness, biceps skinfold thickness, subscapular skinfold thickness and upper suprailiac skinfold thickness were measured. Blood pressure was assessed in the supine position using a validated oscillometric device with appropriate cuff sizes (OMRON HEM 705 CP; Omron, Matsusaka Co, Japan) and the mean of two measurements was used.

Pubertal status was classified into early, middle, late puberty and post pubertal stages based on time since the onset of menstruation (girls) and testicular volume (boys) [18]. The data on menstruation was collected through interview with the participant. Self-assessed testicular volume was determined by participants with the help of a Prader's orchidometer and recorded by study staff.

\section{Interview}

Trained social workers administered the questionnaire, developed from questions already tested and used in other studies. Data collection included demographic information, education and employment, household circumstances, socio-economic status, smoking and alcohol consumption and general health. A short questionnaire was used to interview the mothers.

\section{Blood sample collection and processing}

Fasting blood samples (at least 8 hours) were collected in vacutainers and transferred to an icebox $\left(4-8^{\circ} \mathrm{C}\right)$ to be processed within four hours. Glucose, total cholesterol, HDL cholesterol, triglycerides were assayed on the same day using an autoanalyser (ACE Clinical System; Schiapparelli Biosystems, NJ, USA) and the recommended kits for it (Alfa Wasserman, NJ, USA). Fasting serum insulin concentrations were estimated by radioimmunoassay in batches within four to six weeks [19].

\section{Statistical analysis}

We calculated IR from the homoeostasis model assessment (HOMA) by dividing the product of fasting glucose $(\mathrm{mmol} / \mathrm{L})$ and insulin $(\mathrm{mU} / \mathrm{mL})$ by the constant 22.5 in participants with fasting glucose $<7 \mathrm{mmol} / \mathrm{l}[20]$. Body density was calculated as the log of the sum of four skinfolds by using the equation of Durnin and Wormsley [21]; and then converted into percent body fat by Siri's equation (body fat $\%=(4.95 /$ body density-4.50) $\mathrm{X} 100)$ [22]. Body fat percent was converted to fat mass and fat-free mass by using body weight (total body fat $(\mathrm{kg})=$ body fat $\%$ x weight $(\mathrm{kg}) \times 0.01)$ and (total body fat free mass $(\mathrm{kg})=$ weight $(\mathrm{kg})$-body fat $(\mathrm{kg}))$. Fat and fat-free mass were converted into corresponding indices after dividing them by the square of height in meters [23]. Central to peripheral skin fold ratio was estimated as a ratio of central (subscapular plus suprailiac) to peripheral (biceps plus triceps) skinfolds. Low density lipoprotein cholesterol was measured from triglycerides, total cholesterol, and high density lipoprotein cholesterol by using the Friedewald-Fredrickson equation [24].

Distribution of the anthropometric indices and metabolic risk factors in the whole study cohort, and specifically in girls and boys are presented as means and standard deviations. We used t-tests to compare the means of the variables between boys and girls. Insulin and HOMA scores were positively skewed and we applied log transformations to these variables. To ensure comparability of the models including different anthropometric measures (which have unique measurement units and some are ratios without units) we converted the anthropometric measures to standardized $\mathrm{z}$-scores. These $\mathrm{z}$-scores are standardized scores generated for every observation by using the standard deviations of the individual observations from the observed mean. All models were run using these standardized $\mathrm{z}$-scores.

Associations between anthropometric measures and HOMA, fasting glucose and insulin were tested by using univariable and multivariable linear regression models with generalized estimating equations accounting for clustering by villages. We used models adjusting for age and pubertal development and used separate models for each of the anthropometric measures as the degree of correlation among these indices is very high. Associations of the ratio of FMI to FFMI with HOMA, fasting glucose and insulin was evaluated by using uni variable and multivariable linear regression models accounting for clustering by villages. Multivariable models were additionally adjusted for age and pubertal stage.

Sub group analyses were done within categories of pubertal development separately in boys and girls, to study whether the correlations of these indices with HOMA differed by sexual maturity. Earlier studies have indicated that levels of IR are higher with increasing age and pubertal maturity in adolescent boys and girls [25]. In addition to adjusting for age and pubertal status in our models, we explored the relationship between anthropometric measures and HOMA within categories of pubertal development. 
Citation: Bhattacharya S, Smith GD, Shah SH, Ben-Shlomo Y, Kinra S (2014) Anthropometric Measures and Insulin Resistance in Rural Indian Adolescents. J Biosafety Health Educ 2: 118. doi:10.4172/2332-0893.1000118

Page 3 of 6

\begin{tabular}{|c|c|c|c|c|}
\hline & Total $(\mathrm{N}=1162)$ & Girls (N=535) & Boys $(\mathrm{N}=627)$ & $T$ test $p$ value \\
\hline Age & $15.9,0.9$ & $15.8,0.9$ & $15.9,0.9$ & 0.001 \\
\hline \multicolumn{5}{|l|}{ Anthropometric measures } \\
\hline Height $(\mathrm{cm})$ & $155.4,8.2$ & $151.5,5.7$ & $158.8,8.5$ & $<0.0001$ \\
\hline Weight (kgs) & $41.8,7.2$ & $41.0,6.1$ & $42.4,8.0$ & $<0.0001$ \\
\hline WC $(\mathrm{cm})$ & $61.3,5.5$ & $60.6,5.8$ & $62.0,5.2$ & $<0.0001$ \\
\hline $\mathrm{BMI}\left(\mathrm{kg} / \mathrm{m}^{2}\right)$ & $17.2,2.2$ & $17.8,2.2$ & $16.7,2.1$ & $<0.0001$ \\
\hline WHR & $0.8,0.1$ & $0.8,0.1$ & $0.8,0.1$ & $<0.0001$ \\
\hline Percent body fat (\%) & $18.1,4.6$ & $21.2,3.6$ & $15.4,3.5$ & $<0.0001$ \\
\hline FMI $\left(\mathrm{kg} / \mathrm{m}^{2}\right)$ & $2.6,1.4$ & $3.8,1.1$ & $1.6,0.7$ & $<0.0001$ \\
\hline Lean mass index $\left(\mathrm{kg} / \mathrm{m}^{2}\right)$ & $14.6,1.5$ & $14.1,1.3$ & $15.1,1.5$ & $<0.0001$ \\
\hline Central to peripheral skin ratio & $1.5,0.3$ & $1.4,0.2$ & $1.5,0.2$ & $<0.0001$ \\
\hline \multicolumn{5}{|l|}{ Puberty stages } \\
\hline Early & 171 & 0 & 171 & \\
\hline Middle & 365 & 43 & 322 & \\
\hline Late & 316 & 205 & 111 & \\
\hline Post-pubertal & 272 & 272 & 0 & \\
\hline \multicolumn{5}{|l|}{ CVD risk factors } \\
\hline Total cholesterol (mmol/l) & $3.5,0.7$ & $3.7,0.7$ & $3.3,0.6$ & $<0.0001$ \\
\hline LDL cholesterol (mmol/l) & $2.0,0.6$ & $2.2,0.6$ & $1.9,0.6$ & $<0.0001$ \\
\hline HDL cholesterol (mmol/l) & $1.0,0.2$ & $1.0,0.2$ & $1.0,0.2$ & 0.07 \\
\hline Triglycerides $(\mathrm{mmol} / \mathrm{l})$ & $0.9,0.4$ & $1.0,0.4$ & $0.8,0.3$ & $<0.0001$ \\
\hline Glucose $(\mathrm{mmol} / \mathrm{l})$ & $4.7,0.7$ & $4.7,0.7$ & $4.7,0.6$ & 0.43 \\
\hline Insulin (mU/l) & $19.4,11.2$ & $20.1,11.5$ & $18.8,10.8$ & $<0.0001$ \\
\hline Systolic blood pressure $(\mathrm{mmHg})$ & $109.1,10.2$ & $107.4,9.1$ & $110.6,10.9$ & $<0.0001$ \\
\hline Diastolic blood pressure $(\mathrm{mmHg})$ & $62.4,6.5$ & $62.7,6.5$ & $62.1,6.6$ & 0.04 \\
\hline HOMA & $4.1,2.6$ & $4.2,2.7$ & $4.0,2.5$ & $<0.0001$ \\
\hline
\end{tabular}

Values are presented as means, standard deviations

Table 1: Characteristics of the study population.

\begin{tabular}{|c|c|c|c|c|c|c|c|c|}
\hline & \multicolumn{4}{|c|}{ Girls } & \multicolumn{4}{|c|}{ Boys } \\
\hline & \multicolumn{2}{|c|}{ Unadjusted model* $(n=468)$} & \multicolumn{2}{|c|}{$\begin{array}{l}\text { Minimally } \\
\text { adjusted model }{ }^{\star *}(n=468)\end{array}$} & \multicolumn{2}{|c|}{ Unadjusted model ${ }^{\star}(n=366)$} & \multicolumn{2}{|c|}{$\begin{array}{c}\text { Minimally } \\
\text { adjusted } \text { model }^{\star *}(n=364)\end{array}$} \\
\hline & $\beta(95 \% \mathrm{Cl})$ & $\mathbf{P}$ & $\beta(95 \% \mathrm{Cl})$ & $\mathbf{P}$ & $\beta(95 \% \mathrm{Cl})$ & $\mathbf{P}$ & $\beta(95 \% \mathrm{Cl})$ & $\mathbf{P}$ \\
\hline BMI & $0.03(0.01,0.05)$ & 0.01 & $0.03(0.01,0.06)$ & 0.006 & $0.06(0.03,0.08)$ & $<0.0001$ & $0.06(0.03,0.09)$ & $<0.0001$ \\
\hline FMI & $0.03(0.00,0.05)$ & 0.02 & $0.03(0.01,0.05)$ & 0.02 & $0.05(0.02,0.07)$ & 0.0008 & $0.05(0.02,0.07)$ & 0.001 \\
\hline FFMI & $0.03(0.01,0.05)$ & 0.02 & $0.03(0.01,0.06)$ & 0.007 & $0.06(0.03,0.08)$ & $<0.0001$ & $0.06(0.03,0.09)$ & $<0.0001$ \\
\hline CPR & $0.05(0.02,0.07)$ & $<0.0001$ & $0.05(0.03,0.07)$ & $<0.0001$ & $0.02(-0.01,0.05)$ & 0.14 & $0.02(-0.02,0.05)$ & 0.25 \\
\hline Percent of body fat & $0.02(0.00,0.05)$ & 0.04 & $0.03(0.00,0.05)$ & 0.03 & $0.04(0.01,0.06)$ & 0.004 & $0.03(0.01,0.06)$ & 0.008 \\
\hline WC & $0.03(0.01,0.05)$ & 0.01 & $0.03(0.01,0.05)$ & 0.009 & $0.03(0.01,0.06)$ & 0.01 & $0.03(0.01,0.06)$ & 0.02 \\
\hline WHR & $0.01(-0.01,0.04)$ & 0.24 & $0.01(-0.01,0.04)$ & 0.27 & $-0.03(-0.06,-0.01)$ & 0.01 & $-0.03(-0.06,-0.01)$ & 0.02 \\
\hline
\end{tabular}

${ }^{*}$ Adjusted for village clustering only

${ }^{* *}$ Adjusted for age, pubertal stage and village clustering

Table 2: Association of anthropometric measures with insulin resistance (HOMA) in girls and boys from linear regression models.

All statistical analyses were performed using SAS version 9.2 (Cary NC). No adjustments were made for multiple comparisons.

\section{Results}

\section{Distribution of anthropometric indices and metabolic risk factors}

The characteristics of the study population are represented in Table 1. Of the 1162 adolescents in our study, 535 were female and 627 were male. Participants with missing data on important variables like pubertal status $(n=38)$, body composition $(n=95)$, incomplete questionnaires $(n=31)$, and unavailable blood samples $(n=63)$ were excluded. Children who were fasting for less than eight hours prior to blood sample collection were also excluded from the analyses $(n=8)$. Participants with HOMA scores above $7 \mathrm{mmol} / \mathrm{L}$ were excluded from analyses $(\mathrm{n}=5)$. Glucose and insulin data were available on 1008 adolescents, mainly as insulin assay reagents could not be obtained for the last batch of samples $(n=48)[17]$.

The mean age was 15.9 years, with boys being older $(\mathrm{p}=0.001)$, taller and weighing more than the girls. Our study population was very lean, with a mean BMI of $17.2 \mathrm{~kg} / \mathrm{m}^{2}$. Only $3.6 \%$ of the population was overweight or obese, using age and sex specific BMI cutoffs determined for Indian adolescents, corresponding to the WHO recommended BMI cutoff for overweight $\left(23 \mathrm{~kg} / \mathrm{m}^{2}\right)$ and obese $\left(28 \mathrm{~kg} / \mathrm{m}^{2}\right)$ in South Asians [26]. Girls had an overall higher mean BMI than boys $(\mathrm{p}<0.0001)$ and a higher percentage of body fat. The girls were further along in the pubertal development than boys; with none of the girls in early stages of development, $39.4 \%$ in late stages and $52.3 \%$ in post pubertal stage of development. In comparison, most boys were in middle stages 
Citation: Bhattacharya S, Smith GD, Shah SH, Ben-Shlomo Y, Kinra S (2014) Anthropometric Measures and Insulin Resistance in Rural Indian Adolescents. J Biosafety Health Educ 2: 118. doi:10.4172/2332-0893.1000118

Page 4 of 6

\begin{tabular}{|c|c|c|c|c|c|c|}
\hline & \multirow{2}{*}{$\begin{array}{c}\text { Early }^{\star} \\
\text { Total , all boys }(\mathrm{N}=97)\end{array}$} & \multicolumn{2}{|c|}{ Middle* } & \multicolumn{2}{|c|}{ Late $^{*}$} & \multirow{2}{*}{$\begin{array}{c}\text { Post pubertal }{ }^{*} \\
\text { Total , all girls }(\mathrm{N}=245)\end{array}$} \\
\hline & & Girls $(N=40)$ & Boys (N=200) & Girls (N=184) & Boys (N=67) & \\
\hline & $\beta(95 \% \mathrm{Cl}) ; \mathrm{P}$ & $\beta(95 \% \mathrm{Cl}) ; \mathrm{P}$ & $\beta(95 \% \mathrm{Cl}) ; \mathrm{P}$ & $\beta(95 \% \mathrm{Cl}) ; \mathrm{P}$ & $\beta(95 \% \mathrm{Cl}) ; \mathrm{P}$ & $\beta(95 \% \mathrm{Cl}) ; \mathrm{P}$ \\
\hline BMI & $0.07(0.01,0.13) ; 0.02$ & $0.14(0.04,0.24) ; 0.006$ & $0.06(0.03,0.10) ; 0.0008$ & $0.02(-0.02,0.06) ; 0.40$ & $0.04(-0.02,0.11) ; 0.17$ & $0.03(-0.00,0.06) ; 0.05$ \\
\hline FMI & $0.08(0.01,0.15) ; 0.03$ & $0.10(-0.00,0.20) ; 0.06$ & $0.05(0.01,0.08) ; 0.01$ & $0.03(-0.01,0.07) ; 0.22$ & $0.03(-0.02,0.08) ; 0.26$ & $0.02(-0.01,0.05) ; 0.18$ \\
\hline FFMI & $0.06(0.00,0.11) ; 0.04$ & $0.13(0.04,0.22) ; 0.004$ & $0.06(0.03,0.10) ; 0.0009$ & $0.01(-0.03,0.05) ; 0.67$ & $0.05(-0.02,0.12) ; 0.17$ & $0.03(0.00,0.07) ; 0.03$ \\
\hline CPR & $-0.01(-0.06,0.05) ; 0.95$ & $0.07(-0.00,0.15) ; 0.07$ & $0.04(0.00,0.08) ; 0.03$ & $0.04(0.00,0.09) ; 0.04$ & $-0.01(-0.06,0.04) ; 0.73$ & $0.05(0.02,0.08) ; 0.002$ \\
\hline $\begin{array}{l}\text { Percent } \\
\text { Body Fat }\end{array}$ & $0.06(-0.00,0.11) ; 0.06$ & $0.05(-0.02,0.13) ; 0.18$ & $0.04(0.00,0.07) ; 0.05$ & $0.03(-0.01,0.07) ; 0.15$ & $0.03(-0.03,0.08) ; 0.32$ & $0.01(-0.02,0.04) ; 0.44$ \\
\hline wC & $0.04(-0.02,0.11) ; 0.19$ & $0.06(-0.04,0.16) ; 0.22$ & $0.05(0.01,0.08) ; 0.02$ & $0.04(-0.01,0.08) ; 0.10$ & $0.01(-0.04,0.07) ; 0.65$ & $0.02(-0.00,0.05) ; 0.10$ \\
\hline WHR & $-0.05(-0.10,-0.01) ; 0.03$ & $-0.01(-0.10,0.07) ; 0.70$ & $-0.02(-0.06,0.01) ; 0.21$ & $0.04(-0.00,0.08) ; 0.05$ & $-0.03(-0.09,0.03) ; 0.31$ & $0.01(-0.02,0.04) ; 0.64$ \\
\hline
\end{tabular}

${ }^{*}$ Adjusted for village clustering only

Table 3: Associations of anthropometric measures with insulin resistance (HOMA) in different pubertal stages in girls and boys.

of pubertal development (53.3\%) followed by early (28.3\%) and late $(18.3 \%)$ and none were in the post pubertal stage. Mean fasting insulin levels $(\mathrm{p}=0.006)$ and mean HOMA scores $(\mathrm{p}=0.03)$ were also higher in girls than the boys.

\section{Associations of anthropometric indices with HOMA}

Correlation of the anthropometric measures with HOMA, fasting insulin and fasting glucose are shown in Appendix 1. Associations between anthropometric indices and HOMA in girls and boys are represented in Table 2. Excluding those with missing data on outcome and other variables, 468 girls were included in the analyses and 366 and 364 boys were included in the unadjusted and the adjusted models respectively. BMI, FMI and interestingly FFMI showed consistently strong associations with IR in both boys and girls. FFMI showed associations with IR $(\beta=0.06)$ that were as strong as associations with BMI and FMI $(\beta=0.05)$ in boys even after adjusting for age and pubertal stage. In girls as well, associations of FFMI with IR $(\beta=0.03)$ were as strong as associations with FMI $(\beta=0.03)$. CPR showed strong associations with HOMA in girls but not in boys.

To further evaluate the relationship of FFMI with IR relative to FMI, we explored the associations of the ratio of FMI to FFMI with HOMA (Appendix 3). We found similar associations of FMI/FFMI with HOMA in boys ( $\beta=1.01$; unadjusted and $\beta=0.95$; adjusted models) and in girls ( $\beta=0.29$; unadjusted and $\beta=0.46$; adjusted models).

\section{Associations of anthropometric indices with HOMA within pubertal development stages}

It has been observed in earlier studies that IR (HOMA) in adolescents was higher with increasing age in both boys and girls [25]. We explored the associations by stages of pubertal development in each sex in sub-group analyses (Table 3). FFMI along with BMI and FMI showed consistent strong associations with IR and associations tended to be stronger in earlier stages of pubertal development, contrary to findings from earlier studies. All analyses were done using generalized estimating equations to account for clustering by villages and using standardized $\mathrm{z}$-scores. Since there were no girls in early stage of development, and no boys in post pubertal stage comparisons within these groups by sex were not possible. In middle stages of pubertal development anthropometric indices were relatively more strongly associated with HOMA in girls than in boys, however there were very few girls $(n=40)$ in this stage of pubertal development compared to boys $(\mathrm{n}=200)$.

\section{Associations of anthropometric indices with fasting glucose and fasting insulin}

All analyses evaluating the association of fasting insulin and fasting glucose with anthropometric indices were done using standardized $\mathrm{z}$-scores for the anthropometric measures and adjusted for age and stage of pubertal development in addition to accounting for village clustering. Similar to HOMA, fasting insulin levels showed strong associations with FFMI, BMI and FMI (Appendix 1). Fasting glucose levels did not show any associations with anthropometric measures with the exception of WHR in boys $(\mathrm{p}=0.02)$. We found similar associations of FMI/FFMI with fasting insulin in both boys and girls (Appendix 3).

\section{Discussion}

In this study we evaluated the relationship of anthropometric measures with IR, fasting glucose and fasting insulin in rural Indian adolescents. This is a cohort of rural Indian adolescents, which sets it apart in terms of ethnicity, socioeconomic conditions and geographic region from other studies done on adolescents. We found that FFMI was as strongly associated with IR as FMI and BMI in this study. These observations were consistent in both sexes and within different stages of pubertal development. This is an interesting finding in the light of multiple studies indicating adiposity as a risk for IR [6-8,27].

BMI has proved to be a strong indicator of IR in the adolescents in multiple studies $[16,27,28]$ similar to the findings in our study. By breaking BMI into FMI and FFMI, we can look at the effect of sarcopenic obesity and study the effects of muscle mass and fat mass independently [29]. Our findings indicate that lean mass is as strongly related to IR as fat mass. Hence the observed associations of IR with obesity (and BMI) could be attributed to a larger body mass mainly comprised of fat free/lean mass instead of body fat/adiposity. To further explore this relationship we looked at the association of the ratio of FMI/FFMI with IR, fasting glucose and fasting insulin levels. Strong associations were observed with HOMA and with fasting insulin in both boys and girls. The relationship of lean mass with IR appears to be independent of fat mass. This finding challenges the known relationship between adiposity and IR and emphasizes the need for a better understanding of the mechanisms mediating these associations.

Our observations are contrary to earlier studies that showed an increase in lean muscle mass improves insulin sensitivity [30]. A study in lean Indian men showed that a loss of muscle mass contributes to IR [31] and that a low lean mass compared to fat mass contributes to IR in lean South Asian populations with a high burden of IR and diabetes [30]. Another study emphasized that maintaining a higher muscle mass is instrumental in preventing obesity, IR and diabetes [32]. In view of these associations, there has been an interest on studying skeletal muscle metabolism and its contribution to the development of IR [33].

Interestingly, early studies in women showed that higher lean mass and higher truncal fat content were associated with insulin resistance 
[34] and higher lean mass along with higher visceral fat content was associated with metabolic syndrome [35]. It has been established that adiposity contributes to the development of IR, but interestingly in this cohort of older women a larger lean mass also contributed to metabolic syndrome. The findings of these studies were validated in more recent studies in obese post-menopausal women using dualenergy X-ray absorptiometry to measure body composition and computed tomography (CT) to measure body fat distribution [36,37]. Lean mass was independently associated with insulin levels and glucose homeostasis, and the association of visceral fat with IR was enhanced by an increase in lean mass in post-menopausal women [37]. All these studies were done in obese post-menopausal women. We found similar associations in lean Indian adolescents. Further research on the metabolism of skeletal muscle and its role in the development of IR is required to better understand these associations.

CPR, a measure of central adiposity, was strongly associated with HOMA in girls but not in boys; even within categories of pubertal development. The observed difference between the sexes can be partly explained by the difference in fat distribution in the two sexes and due to the difference in metabolic actions of insulin in men and women, including deposition of adipose tissue [38]. Girls had a higher fasting insulin levels and HOMA scores than boys, and higher BMI and body fat, a difference expected due to hormonal effects [5]. Excess truncal subcutaneous adipose tissue independently predicts IR in post pubertal Indian adolescents [5] and there is evidence to indicate that subcutaneous adipose tissue is more closely correlated to IR than intraabdominal fat [39]. In Indians an excess of visceral adipose tissue is usually accompanied by central subcutaneous adiposity (measured by subscapular/triceps skin fold thickness) [11], the effects of which need to be studied in greater detail.

Though all observed associations were slightly stronger in boys than in girls, but we cannot comment on these gender differences due to the small magnitude of the difference and the possibility of it being a chance occurrence. As pubertal development is known to play a considerable role in these associations [25], we studied the gender differences after adjusting for pubertal maturity. Within the same stage of pubertal development the strength of association in boys was not consistently stronger than in girls. The strength of the associations weakened as the girls and boys moved forward along stages of puberty. This finding was contrary to earlier studies that indicated IR increases with an increase in age and pubertal maturity in adolescents.

Other studies in European adolescents found BMI, WC, weight height ratio, skinfold sum and total fat mass were more strongly associated with IR than with WHR [27]. BMI and subscapular skinfold thickness were most useful in predicting hyperinsulinemia in urban Indian adolescents; and BMI, WC and subscapular skinfold thickness were better at identifying boys with metabolic syndrome than girls [16]. In India, urban populations are typically more overweight, have a different diet and more sedentary lifestyles than rural populations. Moreover, both these studies [16,27], did not look within levels of pubertal maturity to explore differential pubertal development in the two sexes as an explanation for the gender differences they observed.

\section{Strengths and limitations}

We used pubertal development data to stratify the associations of anthropometric measures with HOMA in each sex, which sets our study apart from most other studies that were limited by absence of data on pubertal development. Sexual maturation has considerable influence on insulin sensitivity, and we were able to look within stages of development and compare correlations in both the sexes. As our study population included adolescents from ages 12 years through 18 years, we could explore the relationships of the indices with HOMA in the complete age range of adolescence and study the differences of these associations at different ages and stages of pubertal development.

A limitation of our study is that more accurate measures of body composition such as dual-energy X-ray absorptiometry (DEXA) scan for measurement of total and regional body fat and computerized tomography for measurement of abdominal fat were not used though these have now been obtained as part of a new follow-up so in future work we will be able to examine these more direct measures of adiposity. This analysis from a follow up survey of the Hyderabad Nutrition Trial was cross sectional in nature; hence we could not study progression of IR or other risk factors of diabetes with age but a new follow-up has been recently completed so future work will enable us to examine risk factors for age-related changes. We used a more crude method of pubertal stage classification than full Tanner staging. However a full Tanner staging can be difficult to conduct for a large epidemiological study and the methods we used for determination of pubertal development have been shown to be quite adequate for a broad classification of children into the main stages of maturation and in distinguishing children undergoing peak growth spurt from those before and after [40]. Our cohort is lean and very young; hence the findings are not generalizable to adults and populations burdened with more overweight and obesity.

\section{Conclusion}

In conclusion, we observed a strong association of IR with FFMI similar to associations of BMI and FMI with IR. These associations were consistent across stages of pubertal development in both boys and girls. The association of FFMI with IR as independent of fat mass and hence indicates that lean mass may play an important role in IR contrary to the well-established relationship between adiposity and IR. Further research is needed to better understand the epidemiology of early IR, a predictor of adverse health outcomes later in life and to elucidate the underlying mechanisms of the association of lean mass with IR especially in high risk populations.

\section{Acknowledgement}

Institutional support was provided by the National Institution of Nutrition Hyderabad. We are extremely thankful to our study participants without whom this study would not have been possible.

\section{Contributors}

The study was conceived and designed by Sayanti Bhattacharya, Svati $\mathrm{H}$ Shah, and Sanjay Kinra. Sanjay Kinra was instrumental for implementation of the fieldwork and trained and supervised the field teams. Sayanti Bhattacharya did the statistical analyses and wrote the first draft of the paper. All authors contributed to writing the manuscript and saw and approved the final version. Sanjay Kinra is the guarantor.

\section{Ethics approval}

Ethics committee of the National Institute of Nutrition of India, Hyderabad. Approval was also sought from the village heads and their committees in each of the 29 villages.

\section{References}

1. King H, Aubert RE, Herman WH (1998) Global burden of diabetes, 1995-2025 prevalence, numerical estimates, and projections. Diabetes Care. 21: 14141431.

2. Whincup PH, Gilg JA, Papacosta O, Seymour C, Miller GJ, et al. (2002) Early evidence of ethnic differences in cardiovascular risk: cross sectional comparison of British South Asian and white children. BMJ. 324.

3. Ginsberg HN (2000) Insulin resistance and cardiovascular disease. The Journal of clinical investigation 106: 453-458. 
Citation: Bhattacharya S, Smith GD, Shah SH, Ben-Shlomo Y, Kinra S (2014) Anthropometric Measures and Insulin Resistance in Rural Indian Adolescents. J Biosafety Health Educ 2: 118. doi:10.4172/2332-0893.1000118

4. Misra A, Vikram NK (2004) Insulin resistance syndrome (metabolic syndrome) and obesity in Asian Indians: evidence and implications. Nutrition 20: 482-491.

5. Misra A, Vikram NK, Arya S, Pandey RM, Dhingra V, et al. (2004) High prevalence of insulin resistance in postpubertal Asian Indian children is associated with adverse truncal body fat patterning, abdominal adiposity and excess body fat. Int J Obes Relat Metab Disord. 28:1217-1226.

6. Bacha F, Saad R, Gungor N, Janosky J, Arslanian SA (2003) Obesity, regional fat distribution, and syndrome $X$ in obese black versus white adolescents: race differential in diabetogenic and atherogenic risk factors. J Clin Endocrino Metab. 88: 2534-2540.

7. Krekoukia M, Nassis GP, Psarra G, Skenderi K, Chrousos GP, et al. (2007) Elevated total and central adiposity and low physical activity are associated with insulin resistance in children. Metabolism 56: 206-213.

8. Keskin M, Kurtoglu S, Kendirci M, Atabek ME, Yazici C (2005) Homeostasis model assessment is more reliable than the fasting glucose/insulin ratio and quantitative insulin sensitivity check index for assessing insulin resistance among obese children and adolescents. Pediatrics 115: e500-3.

9. Balkau B, Deanfield JE, Despres JP, Bassand JP, Fox KA, et al. (2007) International Day for the Evaluation of Abdominal Obesity (IDEA): a study of waist circumference, cardiovascular disease, and diabetes mellitus in 168,000 primary care patients in 63 countries. Circulation. 116:1942-1951.

10. Ramachandran A, Snehalatha C, Dharmaraj D, Viswanathan M (1992) Prevalence of glucose intolerance in Asian Indians. Urban-rural difference and significance of upper body adiposity. Diabetes Care 15: 1348-1355.

11. Chandalia M, Abate N, Garg A, Stray-Gundersen J, Grundy SM (1999) Relationship between generalized and upper body obesity to insulin resistance in Asian Indian men. J Clin Endocrinol Metab. 84: 2329-2335.

12. Shelgikar KM, Hockaday TD, Yajnik CS (1991) Central rather than generalized obesity is related to hyperglycaemia in Asian Indian subjects. Diabet Med. 8: 712-717.

13. Yusuf S, Hawken S, Ounpuu S, Bautista L, Franzosi MG, et al. (2005) Obesity and the risk of myocardial infarction in 27,000 participants from 52 countries: a case-control study. Lancet. 366: 1640-1649.

14. Yan W, Wang X, Yao H, Dai J, Zheng Y, et al. (2006) Waist-to-height ratio and BMI predict different cardiovascular risk factors in Chinese children. Diabetes Care 29: 2760-2761.

15. Manios Y, Kourlaba G, Kafatos A, Cook TL, Spyridaki A, et al. (2008) Associations of several anthropometric indices with insulin resistance in children: The Children Study. Acta Paediatr. 97: 494-499.

16. Misra A, Madhavan M, Vikram NK, Pandey RM, Dhingra V, et al. (2006) Simple anthropometric measures identify fasting hyperinsulinemia and clustering of cardiovascular risk factors in Asian Indian adolescents. Metabolism 55: 1569 1573.

17. Kinra S, Rameshwar Sarma KV, Ghafoorunissa, Mendu VV, Ravikumar R et al. (2008) Effect of integration of supplemental nutrition with public health programmes in pregnancy and early childhood on cardiovascular risk in rura Indian adolescents: long term follow-up of Hyderabad nutrition trial. BMJ 337.

18. Tanner JM (1962) Growth at adolescence; with a general consideration of the effects of hereditary and environmental factors upon growth and maturation from birth to maturity. 325.

19. Clark PM, Hales CN (1994) How to measure plasma insulin. Diabetes/ Metabolism Reviews 10: 79-90.

20. Matthews DR, Hosker JP, Rudenski AS, Naylor BA, Treacher DF, et al. (1985) Homeostasis model assessment: insulin resistance and beta-cell function from fasting plasma glucose and insulin concentrations in man. Diabetologia. 28 : 412-419.

21. Durnin JV, Womersley J (1974) Body fat assessed from total body density and its estimation from skinfold thickness: measurements on 481 men and women aged from 16 to 72 years. British Journal of Nutrition 32: 77-97.

22. Siri WE (1993) Body composition from fluid spaces and density: analysis of methods. 1961. Nutrition 9: 480-491.

23. Wells JC (2001) A critique of the expression of paediatric body composition data. Arch Dis Child. 85: 67-72

24. Friedewald WT, Levy RI, Fredrickson DS (1972) Estimation of the concentration of low-density lipoprotein cholesterol in plasma, without use of the preparative ultracentrifuge. Clin Chem. 18: 499-502.
25. Pinhas-Hamiel O, Lerner-Geva L, Copperman NM, Jacobson MS (2007) Lipid and insulin levels in obese children: changes with age and puberty. Obesity (Silver Spring) 15: 2825-2831.

26. Khadilkar VV, Khadilkar AV, Borade AB, Chiplonkar SA (2012) Body mass index cut-offs for screening for childhood overweight and obesity in Indian children. Indian Pediatr. 49: 29-34

27. Kondaki K, Grammatikaki E, Pavon DJ, Manios Y, Gonzalez-Gross M, et al (2011) Comparison of several anthropometric indices with insulin resistance proxy measures among European adolescents: The Helena Study. Eur J Pediatr. 170: 731-739.

28. Hirschler V, Ruiz A, Romero T, Dalamon R, Molinari C (2009) Comparison of different anthropometric indices for identifying insulin resistance in schoolchildren. Diabetes Technol Ther. 11: 615-621.

29. Dulloo AG, Jacquet J, Solinas G, Montani JP, Schutz Y (2010) Body composition phenotypes in pathways to obesity and the metabolic syndrome. Int $\mathrm{J}$ Obes (Lond). 34 Suppl 2:S4-17.

30. Lear SA, Kohli S, Bondy GP, Tchernof A, Sniderman AD (2009) Ethnic variation in fat and lean body mass and the association with insulin resistance. $\mathrm{J}$ Clin Endocrinol Metab. 94: 4696-4702.

31. Unni US, Ramakrishnan G, Raj T, Kishore RP, Thomas T, Vaz M, et al. (2009) Muscle mass and functional correlates of insulin sensitivity in lean young Indian men. European journal of clinical nutrition. 63: 1206-1212.

32. Wolfe RR (2006) Skeletal muscle protein metabolism and resistance exercise. The Journal of nutrition 136: 525S-528S.

33. Krotkiewski M (1994) Role of muscle morphology in the development of insulin resistance and metabolic syndrome. Presse Med. 23:1393-1399.

34. Krotkiewski M, Bjorntorp P (1986) Muscle tissue in obesity with different distribution of adipose tissue. Effects of physical training. International journal of obesity 10: 331-341.

35. You T, Ryan AS, Nicklas BJ (2004) The metabolic syndrome in obese postmenopausal women: relationship to body composition, visceral fat, and inflammation. J Clin Endocrinol Metab. 89: 5517-5522.

36. Karelis AD, Faraj M, Bastard JP, St-Pierre DH, Brochu M, et al. (2005) The metabolically healthy but obese individual presents a favorable inflammation profile. J Clin Endocrinol Metab. 90: 4145-4150.

37. Brochu M, Mathieu ME, Karelis AD, Doucet E, Lavoie ME, et al. (2008) Contribution of the lean body mass to insulin resistance in postmenopausa women with visceral obesity: a Monet study. Obesity (Silver Spring). 16: 10851093

38. Magkos F, Wang X, Mittendorfer B (2010) Metabolic actions of insulin in men and women. Nutrition 26: 686-693.

39. Misra A, Garg A, Abate N, Peshock RM, Stray-Gundersen J, et al. (1997) Relationship of anterior and posterior subcutaneous abdominal fat to insulin sensitivity in nondiabetic men. Obes Res. 5: 93-99.

40. Cameron N (1993) Assessment of growth and maturation during adolescence. Horm Res. 3: 9-17. 